DOI: $10.217672573-5365.100018$

\title{
Sonic Hedgehog in Nasal Mucus is a Biomarker for Smell Loss in Patients with Hyposmia
}

\section{Robert I Henkin*, Suzanna Hosein, William A Stateman and Alexandra B Knoppel}

Center for Molecular Nutrition and Sensory Disorders, The Taste and Smell Clinic, Washington, USA

*Corresponding author: Robert I Henkin, MD, Center for Molecular Nutrition and Sensory Disorders, 5125 MacArthur Blvd. NW, \#20, Washington, D.C. 20016, USA, Tel: 202-364-4180; Fax: 202-364-9727; E-mail: doc@tasteandsmell.com

Rec date: June 02, 2016; Acc date: July 06, 2016; Pub date: July 11, 2016

Copyright: (c) 2016 Henkin Rl, et al. This is an open-access article distributed under the terms of the Creative Commons Attribution License, which permits unrestricted use, distribution, and reproduction in any medium, provided the original author and source are credited.

Citation: I. Henkin R. Sonic hedgehog in nasal mucus is a biomarker for smell loss in patients with hyposmia. Cell Mol Med. $2016,2: 2$.

\section{Abstract}

Title: Sonic hedgehog in nasal mucus is a biomarker for smell loss in patients with hyposmia

Background: Many chemical moieties have been identified in nasal and olfactory mucus related to cellular activity, cell signaling and olfaction. Sonic hedgehog (Shh) has been identified as a growth factor in taste buds but not in olfactory receptor tissues. We wished to determine if Shh were present in nasal mucus and, if present, does it relate to smell function and smell loss (hyposmia).

Methods and findings: Shh was evaluated in nasal mucus in 14 normal volunteers and 44 patients with smell dysfunction of several etiologies. Nasal mucus was collected over a 1-4 day period in a $50 \mathrm{ml}$ plastic container, transferred to a $12 \mathrm{ml}$ plastic tube, centrifuged at $18,000 \mathrm{rpm}$ for $45-55$ minutes, the supernatant transferred to PCR tubes and frozen at $20^{\circ} \mathrm{C}$ until analyzed. All samples were analyzed by use of a sensitive spectrophotometric ELISA. Shh was found in nasal mucus in all normal subjects and in hyposmia patients. Levels in hyposmia patients of several etiologies were significantly lower than in normal. Levels decreased as subjects aged.

Conclusions: This is the first systematic demonstration of Shh in nasal mucus in normal subjects and in hyposmia patients. Its presence is consistent with its role as a cell signaling moiety and growth or transcription factor related to olfactory receptor function. Its measurement in lower than normal concentrations in hyposmic patients may indicate that it can serve as a biomarker for smell loss in these patients. Its measurement can help to identify patients with hyposmic on an objective basis and help to define the biochemical parameters of their smell loss. Further studies can assist in determination of the specific role for this moiety in olfaction.

\section{Introduction}

Investigators have identified several chemical moieties in nasal mucus [1,2], in olfactory mucus and in mucus from olfactory mucosa [3-8] and related its presence to regulation of cellular activity, cell signaling in the olfactory mucosa [3-8] or in pathology of the upper airways [9-12]. Levels of one of these moieties, olfactomedin, identified as an olfactory glycoprotein [3], was lower than normal in animals with loss of smell (hyposmia); increasing these levels was associated with what was characterized as normal olfactory function [4]. However, there are many moieties in nasal mucus in humans not identified through these and other analyses [13]. Chief among these are adenylyl cyclases [14,15] and their downstream metabolites cyclic adenosine monophosphate (cAMP) and cyclic guanosine monophosphate (cGMP) [16,17]. These latter moieties were found decreased in hyposmic patients compared to normal subjects $[16,17]$. Sonic hedgehog (Shh) has been characterized as a critical factor in cellular growth and development of taste receptors $[18,19]$ with its absence associated with inhibition of growth and development of receptors of these sensory organs [20]; however, it has not been identified to play a role in olfaction per se.

Based upon these [18-20] and other studies [21] we and other before us recognized that moieties in nasal mucus, including several cytokines [21] and several drugs [22], could act as regulators of cellular function and cellular signaling [21] and cytokines could be identified as so-called growth or transcription factors [23] which stimulated stem cells in the olfactory epithelium to induce stimulation, growth and perpetuation of olfactory receptors to maintain olfactory function [24]. Inhibition of secretion of these nasal mucus moieties initiated smell loss [24] whereas treatment which increased these moieties improved or even restored olfactory function to or towards normal [24].

Because of the large number of hyposmic patients in the US [24] these studies generated our interest to search for other nasal mucus moieties that might act as growth factors involved with maintaining olfactory function in humans. This search resulted in a preliminary report in which Shh was identified in nasal mucus [25]. 
In this study we report substantive studies which identify the presence of Shh in nasal mucus of normal subjects and of patients with hyposmia.

\section{Methods}

\section{Subjects}

Normal Subjects: Fourteen volunteers with normal smell and taste function were studied. These subjects were four men, 10 women, aged 44-82 y, $61 \pm 3 y$ (Mean \pm SEM) who were either patients who presented to The Taste and Smell Clinic in Washington, DC for evaluation of symptoms unrelated to smell loss or who were employees of the Taste and Smell Clinic who volunteered for the study. Subjects were selected in a consecutive manner and included all subjects who volunteered for the study. All subjects stated that they had normal smell function. Olfactometry by use of systematic tests of smell function [24] was within normal limits for each subject.

Patients: Forty-four patients, aged $10-88$ y, $56 \pm 3$ y (Mean \pm SEM) who presented to The Taste and Smell Clinic in Washington, DC for evaluation and treatment of smell dysfunction were also subjects of the study. Patients reported presence of smell loss six months to 10 years $(5 \pm 2$ y) prior to their initial clinic visit. Patients were selected consecutively from patients evaluated at The clinic from 2012-2013. Patients were 24 men, aged $12-88$ y, $54 \pm 4$ y and 20 women, aged $10-84$ y, $51 \pm 5$ y. All patients stated that they had a smell loss. Olfactometry by use of systematic standardized tests of smell function indicated significant smell acuity impairment with increased detection and recognition thresholds (loss of sensitivity) and decreased magnitude estimation for each of four odors (pyridine, nitrobenzene, thiophene and amyl acetate) [24]. One patient not only had acuity loss but also dysgeusia (distorted taste sensitivity) and oropyrosis [26].

Patients exhibited six etiologies related to their smell loss: post-influenza-like hyposmia (PIHH) [27] (10 patients), allergic rhinitis [28] (15 patients), congenital hyposmia [29] (nine patients), head injury [30] (eight patients), post general anesthesia [31] (one patient) and dysgeusia and oropyrosis [26] (one patient). Patients were not taking any medications at the time this study was performed.

Physical examination of the upper airways by use of anterior rhinoscopy or nasal endoscopy was within normal limits in each patient. Computer tomography or magnetic resonance imaging of brain in each patient revealed the presence of olfactory clefts and bulbs in each patient.

Measurements of Shh in nasal mucus were performed in all normal subjects and hyposmic patients.

Study protocol was approved by the Chesapeake Institute Review Board. Each patient and subject agreed to participate in the study and signed an informed consent participation form.

\section{Biochemical procedures}

Patients and volunteers collected all nasal mucus spontaneously produced over a period of 1-4 days into a $50 \mathrm{ml}$ plastic tube. Patients collected all nasal mucus generated spontaneously over each waking hour over each 24 hour period using continuous collection into the $50 \mathrm{ml}$ plastic tube. All samples were refrigerated overnight for collections longer than 24 hours.

Each sample was transferred to a $12 \mathrm{ml}$ plastic tube and centrifuged in a Sorvall RC5C Plus centrifuge at $18,000 \mathrm{rpm}$ for 45-55 minutes. Supernatant was transferred to PCR tubes and stored at $20^{\circ} \mathrm{C}$ until analyzed.

Each sample was analyzed by use of a sensitive spectrophotometric ELISA technique obtained from Abcam Inc. (Cambridge, MA). Analysis of duplicate samples agreed within $5 \%$. All analyses were made independent of the knowledge of the status of any subject. Only after all samples were analyzed were results tabulated and samples classified in relationship to subject status.

Results were analyzed such that mean \pm SEM of nasal mucus Shh levels were obtained with results of normal subjects and hyposmic patients compared using Student $t$ test with $p<0.05$ considered significant. Each set of values was obtained independently and not evaluated or compared until each set was completely analyzed.

\section{Results}

Shh was found to be present in nasal mucus in all normal volunteers and in all patients with hyposmia (Table 1). Mean Shh levels in hyposmic patients were significantly lower than in normal subjects. These levels were less than $2 \%$ those found in normal subjects (Table 1).

Table 1: Sonic Hedgehog in nasal mucus in normal subjects and in patients with Hyposmia.

\begin{tabular}{|l|l|}
\hline Subjects & Sonic Hedgehog ${ }^{*}$ \\
\hline Normals (14) & $7538 \pm 1105^{+}$ \\
\hline Patients (44) & $149 \pm 2^{\mathrm{A}}$ \\
\hline $\begin{array}{l}\text { ( ) Subject Number; }{ }^{*} \text { In Pg/Ml; }{ }^{+} \text {Mean } \pm \text { SEM } \\
\text { with respect to normal; }{ }^{\text {A } P<0.001}\end{array}$ \\
\hline
\end{tabular}

Mean Shh levels in patients with various etiologies related to the cause of their smell loss varied widely (Table 2).

Table 2: Sonic Hedgehog in nasal mucus in patients with Hyposmia classified by etiology of smell loss.

\begin{tabular}{|l|l|}
\hline Subjects & Sonic Hedgehog ${ }^{*}$ \\
\hline Etiology of Hyposmia (44) & $1537 \pm 159^{+, A}$ \\
\hline Post-Influenza-Like Hyposmia (10) & $34 \pm 2^{\mathrm{A}}$ \\
\hline Allergic Rhinitis (15) &
\end{tabular}




\begin{tabular}{|l|l|}
\hline Congenital Hyposmia (9) & $180 \pm 12^{\mathrm{A}}$ \\
\hline Head Injury (8) & $1396 \pm 252^{\mathrm{A}}$ \\
\hline Dysgeusia With Oropyrosis (1) & 226 \\
\hline Post General Anesthesia (1) & 1.3 \\
\hline
\end{tabular}

( ) Subject number; ${ }^{*}$ in $\mathrm{pg} / \mathrm{ml}$; ${ }^{+}$Mean \pm SEM; with respect to normal levels (Table 1) ${ }^{A} p<0.001$

The patient with hyposmia following general anesthesia exhibited the lowest level of any patient followed in order by patients with allergic rhinitis, congenital hyposmia, the patient with dysgeusia and oropyrosis, head injury and PIHH. Mean Shh levels of patients were significantly lower than in normal subjects.

Characterized by age there is a consistent decrease in nasal mucus Shh in hyposmic patients as they age (Table 3).

Table 3: Sonic Hedgehog in nasal mucus in patients with Hyposmia categorized by age.

\begin{tabular}{|l|l|}
\hline Age [Y] & Sonic Hedgehog ${ }^{*}$ \\
\hline $10-30(9)$ & $235 \pm 97^{+}$ \\
\hline $31-50(9)$ & $53 \pm 25$ \\
\hline $51-70(17)$ & $36 \pm 19$ \\
\hline $71-90(9)$ & $23 \pm 14$ \\
\hline ( ) Subject Number; ${ }^{*}$ In Pg/Ml; ${ }^{+}$Mean \pm Sem \\
\hline
\end{tabular}

\section{Discussion}

Hedgehog proteins belong to a family of extracellular signaling molecules involved in regulation of multiple physiological processes including invertebrate and vertebrate embryo development [32]. Vertebrate organisms express multiple forms of hedgehog. In mammals there are three hedgehogs-Sonic hedgehog (Shh), Indian hedgehog (Ihh) and Desert hedgehog (Dhh) [33]. Shh plays an important role in several developmental processes involving induction of dopaminergic [34] and cholinergic neurons [35], development of the retina [36] and in activating neural stem cells [37].

Shh is synthesized as a $45 \mathrm{kD}$ precursor protein that is cleaved auto catalytically to yield a $20 \mathrm{kD} \mathrm{N}$-terminal fragment with a cholesterol molecule covalently attached to the Cterminal glycine and a $25 \mathrm{kD}$ C-terminal fragment [38]. Its crystal structure has been determined [39]. It is structurally homologous to several zinc-dependent hydrolases [40] and it contains one zinc atom coordinated by two histidines and a glutamate residue [41] similar to the presence of zinc in the structure of the taste bud growth factor gustin (carbonic anhydrase (CA) $\mathrm{VI}$ ) [42]. Elimination of zinc from either Shh or CA VI inhibits their respective activity [41,42]. CA VI and zinc components have also been shown to play a role in adenylyl cyclase metabolism by acting as a potent activator of phosphodiesterase [43].
Shh has been shown to play a regulatory and signaling role in organisms as diverse as drosophila [33] and Caenorhabditis elegans [44] as in mammalian systems [18-21]. It has been shown to play a regulatory and structural role in multiple sensory systems including hearing [45], involving the cochlea [46], vision, involving retinal receptors [47], taste, involving basal cell function of taste receptors $[18,19]$ and growth of taste papillae [20]. Disruption of Shh signaling causes inhibition of growth and patterning of these sensory receptors [18-20]. While there have been no studies dealing with Shh in olfactory function per se multiple studies involving the primary essential role of Shh in cilia assembly and regulation have been published $[48,49]$. Interference of Shh signaling in these systems inhibited cilia function. Shh has also been shown to play a role in neurogenesis and functional plasticity in multiple neuronal circuits [50] including coordination of growth of patterning of several brain structures, including the cerebellum [51] and olfactory bulb [52].

Results of the present study indicate that Shh is present in nasal mucus in both normal subjects and in patients with hyposmia. Levels of nasal mucus Shh in hyposmic patients were significantly lower than in normal subjects. Levels of nasal mucus Shh decrease with age. These results are consistent with reports of decreased olfactory acuity as people age [53]. Measurements of lower than normal nasal mucus levels of Shh in hyposmic patients may serve as a marker for the presence of smell loss in hyposmic patients.

The study has several limitations. The number of normal subjects and hyposmic patients studied was relatively small. In addition, results within each subject category were variable. However, despite the relatively small number of subjects and their variability differences between normals and patients were significant and reflect the presence of Shh in nasal mucus in both groups of subjects.

Low levels of nasal mucus Shh are present in patients with the major pathologies responsible for hyposmia; as such, low levels of nasal mucus Shh may reflect a chemical biomarker by which these patients can be identified. This measurement is important since it can assist in the diagnosis of hyposmia in an objective manner.

\section{Conclusion}

This is the first systematic demonstration of Shh in nasal mucus. Its presence is consistent with its role as a cell signaling moiety and growth factor involved in olfactory function. Nasal mucus Shh may serve as a chemical biomarker to identify patients with hyposmia of various etiologies on an objective basis and to assist in defining the biochemical cause of their loss.

\section{Funding}

There are no sources of funding to declare. 


\section{Conflict of Interest}

Robert I. Henkin is a member of the board of directors of Cyrano Therapeutics. None of the other authors has a conflict of interest, financial or otherwise with respect to the publication of this manuscript

\section{References}

1. Bogdanffy MS (1990) Biotransformation enzymes in the rodent nasal mucosa: the value of a histochemical approach. Environ Health Perspect 85: 177-186.

2. Cole AM, Kim YH, Tahk S, Hong T, Weis P, et al. (2001) Calcitermin, a novel antimicrobial peptide isolated from human airway secretions. FEBS Lett 504: 5-1

3. Snyder DA, Rivers AM, Yokoe H, Menco BP, Anholt RR (1991) Olfactomedin: purification, characterization and localization of a novel olfactory glycoprotein. Biochemistry 30:9143-9153.

4. Li R, Diao H, Zhao F, Xiao S, El Zowalaty AE, et al. (2015) Olfactomedin 1 deficiency leads to defective olfaction and impaired female fertility. Endocrinology 156: 3344-3357.

5. Ferrari CC, Carmanchahi PD, Aldana Marcos HJ, et al. (1999) Identification and localisation of glycoconjugates in the olfactory mucosa of the armadillo Chaetophractus villosus. J Anat 194(Pt 3): 395-405.

6. Krishna NS, Getchell ML, Tate SS, Margolis FL, Getchell TV, et al. (1992) Glutathione and gamma-glutamyl transpeptidase are differentially distributed in the olfactory mucosa of rats. Cell Tissue Res 270: 475-484.

7. Bal RS, Anholt RR (1993) Formation of the extracellular mucous matrix of olfactory neuroepithelium: identification of partially glycosylated and nonglyosylated precursors of olfactomedin. Biochemistry 32: 1047-1053.

8. Franceschini V, Lazzari M, Ciani F (2003) Surface glycoconjugates in the olfactory system of Ambystoma mexicanum. J Morphol 256: 301-305.

9. Proud D, Togias A, Naclerio RM, Crush SA, Norman PS, et al. (1983) Kinins are generated in vivo following nasal airway challenge of allergic individuals with allergen. J Clin Invest 72: 1678-1685.

10. Lund VJ, Henderson B, Song Y (1993) Involvement of cytokines and vascular adhesion receptors in the pathology of frontoethmoidal mucocoeles. Acta Otolaryngol 113: 540-546.

11. Ruffoli R, Ursino F, Fattori B, Scavuzzo MC, Paparelli A, et al. (2004) Distribution of 3-nitrotyrosine in the nasal polyps of atopic patients. Laryngoscope 114: 118-125.

12. Shuter J, Hatcher VB, Lowy FD (1996) Staphylococcus aureus binding to human nasal mucin. Infect Immun 64: 310-318.

13. Henkin RI, Doherty AE, Martin BM (2000) Nasal seroproteins: a new frontier in the exploration of physiology and pathology of nasal and sinus disease. In: Veldman JE, Passàli D, Lim DJ, editors. New Frontiers in Immunobiology. The Hague: Kugler. pp. 127-152.

14. Sinnarajah S, Dessauer CW, Srikujmar D, Chen J, Yuen J, et al. (2001) RGS2 regulates signal transduction in olfactory neurons by attenuating activation of adenylyl cyclase III. Nature 409: 1051-1055.
15. Wong ST, Trinh K, Hacker B, Chan GC, Lowe G, et al. (2000) Disruption of the Type III adenylyl cyclase gene leads to peripheral and behavioral anosmia in transgenic mice. Neuron 27: 487-497.

16. Henkin RI, Velicu I (2008) cAMP and cGMP in nasal mucus: relationships to taste and smell dysfunction, gender and age. Clin Invest Med 31: E71-E77.

17. Henkin RI, Velicu I (2008) cAMP and cGMP in nasal mucus related to severity of smell loss in patients with smell dysfunction. Clin Invest Med 31: E78-E84.

18. Miura $\mathrm{H}$, Kato $\mathrm{H}$, Kusakabe $\mathrm{Y}$, Tagami M, Miura-Ohnuma J, et al. (2004) A strong nerve dependence of sonic hedgehog expression in basal cells in mouse taste bud and an autonomous transcriptional control of genes in differentiated taste cells. Chem Senses 29: 823-831.

19. Miura H, Scott JK, Harada S, Barlow LA (2014) Sonic hedgehog-expressing basal cells are general post-mitotic precursors of functional taste receptor cells. Dev Dyn 243: 1286-1297.

20. Hall JM, Bell ML, Finger TE (2003) Disruption of sonic hedgehog signaling alters growth and patterning of lingual taste papillae. Dev Biol 255: 263-277.

21. Henkin RI, Velicu I, Schmidt L (2013) Cell signaling in smell loss (hyposmia). FASEB J 27: 601.4.

22. Lötsch J, Geisslinger G, Hummel $T$ (2012) Sniffing out pharmacology: interactions of drugs with human olfaction. Trends Pharmacol Sci 33: 193-199.

23. Henkin RI (2011) Growth factors in olfaction. In: Preedy VR, editor. The Handbook of Growth and Growth Monitoring in Health and Disease. Vol II. New York: Springer-Verlag. pp. 1417-1436.

24. Henkin RI, Levy LM, Fordyce A (2013) Taste and smell function in chronic disease: A review of clinical and biochemical evaluation of taste and smell dysfunction in over 5000 patients at The Taste and Smell Clinic in Washington, DC. Am J Otolaryngol 34: 477-489

25. Henkin RI, Hosein S, Stateman W, Knöppel A (2015) Oral theophylline improves smell function by increasing nasal mucus sonic hedgehog (Shh). FASEB J 29: 840.6.

26. Henkin RI, Gouliouk V, Fordyce A (2012) Distinguishing patients with glossopyrosis from those with oropyrosis based upon clinical differences and differences in saliva and erythrocyte magnesium. Arch Oral Biol 57: 205-210.

27. Henkin RI, Larson AL, Powell RD (1975) Hypogeusia, dysgeusia, hyposmia and dysosmia following influenza-like infection. Ann Otol Rhin Laryngol 84: 672-682.

28. Church JA, Bauer H, Bellanti JA, Satterly RA, Henkin RI (1978) Hyposmia associated with atopy. Ann Allergy 40: 105-109.

29. Henkin RI, Levy LM (2002) Functional MRI of congenital hyposmia: brain activation of odors and imagination of odors and tastes. J Comput Assist Tomogr 26: 39-61.

30. Schechter PJ, Henkin RI (1974) Abnormalities of taste and smell after head trauma. J Neurol Neurosurg Psychiatry 37: 802-810.

31. Henkin RI (1995) Altered taste and smell after anesthesia: cause and effect? Anesthesiology 83: 648-649.

32. Hammerschmidt M, Brook A, McMahon AP (1997) The world according to hedgehog. Trends Genet 13: 14-21. 
33. Echelard Y, Epstein DJ, St-Jacques B, Shen L, Mohler J, et al. (1993) Sonic hedgehog, a member of a family of putative signaling molecules, is implicated in the regulation of CNS polarity. Cell 75: 1417-1430.

34. Hynes $M$, Porter JA, Chiang $C$, Chang D, Tessier-Lavigne $M$, et al. (1995) Induction of midbrain dopaminergic neurons by Sonic hedgehog. Neuron 15: 35-44.

35. Ericson J, Muhr J, Placzek M, Lints T, Jessell TM, et al. (1995) Sonic hedgehog induces the differentiation of ventral forebrain neurons: a common signal for ventral patterning within the neural tube. Cell 81: 747-756.

36. Jensen AM, Wallace VA (1997) Expression of Sonic hedgehog and its putative role as a precursor cell mitogen in the developing mouse retina. Development 124: 363-371.

37. Ahn S, Joyner AL (2005) In vivo analysis of quiescent adult neural stem cells responding to Sonic hedgehog. Nature 437: 894-897.

38. Bumcrot DA, Takada R, McMahon AP (1995) Proteolytic processing yields two secreted forms of sonic hedgehog. Mol Cell Biol 15: 2294-2303.

39. Hall TM, Porter JA, Beachy PA, Leahy DJ (1995) A potential catalytic site revealed by the 1.7-A crystal structure of the amino-terminal signalling domain of Sonic hedgehog. Nature 378: 212-216.

40. Murzin AG (1996) Structural classification of proteins: new superfamilies. Curr Opin Struct Biol 6: 386-394.

41. Day ES, Wen D, Garber EA, Hong J, Avedissian LS (1999) Zincdependent structural stability of human Sonic hedgehog. Biochemistry 38: 14868-14880.

42. Thatcher BJ, Doherty AE, Orvisky E, Martin BM, Henkin RI (1998) Gustin from human parotid saliva is carbonic anhydrase VI. Biochem Biophys Res Commun 250: 635-641.

43. Law JS, Nelson NR, Watanabe K, Henkin, RI (1987) Human salivary gustin is a potent activator of calmodulin-dependent brain phosphodiesterase. Proc Natl Acad Sci USA 84: 1674-1678.

44. Corbit KC, Aanstad P, Singla V, Norman AR, Stainier DY, et al. (2005) Vertebrate smoothened functions at the primary cilium. Nature 437: 1018-102
45. Driver EC, Pryor SP, Hill P, Turner J, Rüther U, et al. (2008) Hedgehog signaling regulates sensory cell formation and auditory function in mice and humans. J Neurosci 28: 7350-7358.

46. Riccomagno MM, Martinu L, Mulheisen M, Wu DK, Epstein DJ (2002) Specification of the mammalian cochlea is dependent on Sonic hedgehog. Genes Dev 16: 2365-2378.

47. Wall DS, Mears AJ, McNeill B, Mazerolle C, Thurig S, et al. (2009) Progenitor cell proliferation in the retina is dependent on Notchindependent Sonic hedgehog/Hes1 activity. J Cell Biol 184: 101-112.

48. Breunig JJ, Sarkisian MR, Arellano JI, Morozov YM, Ayoub AE, et al. (2008) Primary cilia regulate hippocampal neurogenesis by mediating sonic hedgehog signaling. Proc Natl Acad Sci USA 105: 13127-13132.

49. Park TJ, Haigo SL, Wallingford JB (2006) Ciliogenesis defects in embryos lacking inturned or fuzzy function are associated with failure of planar cell polarity and Hedgehog signaling. Nat Genet 38: 303-311.

50. Lledo PM, Alonso M, Grubb MS (2006) Adult neurogenesis and functional plasticity in neuronal circuits. Nat Rev Neurosci 7: 179-193.

51. Dahmane N, Ruiz-i-Altaba A (1999) Sonic hedgehog regulates the growth and patterning of the cerebellum. Development 126: 3089-3100.

52. Spassky N, Heydon K, Mangatal A, Jankovski A, Olivier C, et al. (2001) Sonic hedgehog-dependent emergence of oligodendrocytes in the telencephalon: evidence for a source of oligodendrocytes in the olfactory bulb that is independent of PDGFRalpha signaling. Development 128: 4993-5004.

53. Murphy $C$, Schubert $C R$, Cruickshanks KJ, Klein BE, Klein R, et al. (2002) Prevalence of olfactory impairment in older adults. JAMA 288: 2307-2312. 